\title{
INFLUÊNCIA DAESTRUTURA DO SOLO NA DISTRIBUIÇÃO E NA MORFOLOGIA DO SISTEMA RADICULAR DO MILHO SOB TRÊS MÉTODOS DE PREPARO(1)
}

\author{
W. M. P. ME LLO IVO(2) \& J . MIELNICZUK ${ }^{(3)}$
}

\begin{abstract}
RESUMO
O estudo da distribuição de raízes no solo é um método adequado para se detectarem as condições adversas ou não ao seu desenvolvimento, bem como para avaliar o efeito das alterações introduzidas por sistemas de preparo do solo. Sendo assim, o objetivo deste trabalho foi avaliar o efeito de métodos de preparo sobre determi nadas características do solo e, por conseguinte, sobre o desenvolvimento do sistema radicular do milho. Para tal, foi utilizado um experimento de campo, instalado em um solo Podzólico Vermelho-E scuro com cinco anos de utilização por preparo convencional, reduzido e semeadura direta, na sucessão aveia + trevo/milho. Para observar as modificações estruturais do solo, usou-se o método do perfil cultural adaptado, acompanhado por determinações de densidade do solo, porosidade total, macro e microporosidade e resistência ao penetrômetro. Os métodos da parede do perfil e do monolito (prancha com pregos) foram utilizados para determinar a distribuição e morfologia das raízes. Nos mapas estruturais descritos, observou-se que os modos de organização provocados pelos tratamentos explicaram parcialmente a presença das raízes no perfil. As plantas submetidas à semeadura direta, quando comparadas às do preparo convencional, tiveram o crescimento ini cial das raízes diferindo do padrão diagonal normal e, ao final do ciclo, apresentaram raízes com maior raio médio nas profundidades de 10-15 e 25-35 cm e mostraram a densidade de comprimento $\left(\mathrm{cm} \mathrm{cm}^{-3}\right)$ maior na camada superficial $(0-5 \mathrm{~cm})$ e menor na camada de $10-15 \mathrm{~cm}$. Os sistemas de preparo não afetaram a massa seca de raízes e o rendimento dos grãos de milho.
\end{abstract}

Termos de indexação: raiz, preparo do solo, plantio direto, perfil cultural.

\footnotetext{
(1) Parte da Tese de Mestrado da primeira autora, apresentada ao Departamento de Sol os da Universidade Federal do Rio Grande do Sul (UFRGS), Porto Alegre (RS). Recebido para publicação em abril de 1997 e aprovado em outubro de 1998.

(2) Pesquisadora da Embrapa Tabuleiros Costeiros, UEP de Rio Largo. Caixa Postal 2013, CEP 57061-970 Maceió (AL). E-mail: gaba@dialnet.com.br.

(3) Professor do Departamento de Solos da Universidade Federal do Rio Grande do Sul. Caixa Postal 776, CEP 90001-970 Porto Alegre (RS). Bolsista do CNPq.
} 


\title{
SUMMARY: INFLUENCE OF SOIL STRUCTURE ON THE DISTRIBUTION AND MORPHOLOGY OF CORN ROOTS UNDER THREE TILLAGE METHODS
}

\begin{abstract}
Thestudy of root distribution in soils is an adequatemethod to detect adverseconditions to root devel opment, and evaluate the effect of soil alterations caused by soil management systems. With theseobjectives, a field experiment was carried out for fiveyears on a Pal eudult soil with oat + clover/ maize under conventional tillage, reduced tillage and no tillage To observethestructural modifications of thesoil, an adaptation of the "profil cul tural" method, was used al ong with thedetermination of bulk density, total porosity, macro and microporosity and penetrometer resistance of thesoil. Therooting profileand thenail board methods were used to determineroot distribution and morphol ogy. It was observed in thestructural maps described that the treatment arrangements partially explained the presence of the roots in theprofile In the 10-15 cm and 25-35 cm layers, theplants growing under notillageshowed roots with radius greater than those under conventional tillage Thedensity $\left(\mathrm{cm} \mathrm{cm}^{-3}\right)$ was greater at the surface $(0-5 \mathrm{~cm})$ and smaller in the $10-15 \mathrm{~cm}$ layer. The soil tillage systems did not affect dry mass of the roots nor the yield of maize
\end{abstract}

Index terms: root, soil tillage direct drilling, "profil cultural".

\section{NTRODUÇÃO}

Nos últimos anos, métodos de preparo de solo, como o reduzido e a semeadura direta, vêm sendo adotados em substituição aos preparos convencionais. Tais métodos, por não revolverem o solo ou revolvêlo parcialmente, podem provocar no perfil estruturas diferentes daquelas resultantes dos preparos convencionais, as quais podem influenciar o desenvol vimento do sistema radicular das plantas, e, por conseqüência, sua produtividade.

Trabalhos referentes ao efeito dos diferentes preparos nas propriedades do solo vêm sendo desenvolvidos com maior freqüência (Vieira \& Muzilli, 1984; Roth et al., 1988), sendo mais escassas as informações relacionadas com os efeitos dessas propriedades sobre o sistema radicular das culturas. Sendo assim, o objetivo deste estudo foi avaliar os efeitos de três métodos de preparo do solo sobre determinadas características do solo e associá-los à distribuição e morfologia de raízes de milho em diferentes fases deseu desenvol vimento, relacionandose estes resultados com o rendimento da cultura.

\section{MATERIAL E MÉTODOS}

O presente trabal ho foi realizado em um experimento com cinco anos de duração, instalado em 1985 e localizado na Estação Experimental Agronômica da UFRGS, município de Eldorado do Sul (RS), em solo Podzólico Vermelho-Escuro. Os dados analisados referem-se ao milho plantado em 1989.
Os métodos de preparo estudados foram preparo convencional (aração egradagens), preparo reduzido (escarificação) e plantio direto. O sistema deculturas utilizado foi aveia + trevo/milho, sendo as avaliações feitas no período do verão, com a cultura do milho (Zea mays L.), em parcelas de $50 \mathrm{~m}^{2}$. Foram efetuadas amostragens para determinar a distribuição de raízes e descrever e caracterizar os modos de organização dos elementos estruturais criados no solo pelos preparos em quatro épocas, a saber: 20 dias após o plantio (milho com quatro fol has), 30 dias (oito fol has), 58 dias (doze fol has) e 74 dias (quatorze folhas); coincidindo a última ao estádio de floração plena. Neste estádio, foram retiradas as amostras para caracterização morfológica das raízes.

A organização dos elementos estruturais do solo foi avaliada em todas as épocas por meio da adaptação da técnica do perfil cultural de Gautroneau \& Manichon (1987), que consiste na descrição de perfis antropizados com vistas em obter diagnósticos e prognósticos mais especificamente ligados aos diferentes sistemas de cultivo e populações vegetais. Dos níveis de organização propostos por Gautronneau \& Manichon (1987), considerou-se, no presente estudo, apenas o modo de organização dos torrões no perfil do solo, sendo o estado interno destes caracterizado em laboratório (Quadro 1). Além dessa adaptação, a descrição do perfil foi realizada sobre as placas de pregos retiradas para posterior amostragem das raízes, e não em trincheiras exigidas pelo método original, as quais são maiores por possuírem largura dependente do implemento utilizado. 


\section{Quadro 1. Descrição do modo de organização dos elementos estruturais (torrões e, ou, agregados). Adaptado de Grautronneau \& Manichon, 1987}

\begin{tabular}{lll}
\hline $\begin{array}{c}\text { Organização dos elementos } \\
\text { estruturais do solo }\end{array}$ & Modo de organização & Definição \\
\hline Não se individualiza em torrões & Maciço (M) & $\begin{array}{l}\text { Ausência de porosidade estrutural ou muito pouco } \\
\text { desenvolvida. Pode ocorrer porosidade biológica } \\
\text { discernível (UD) }\end{array}$ \\
$\begin{array}{l}\text { Unido facilmente } \\
\text { discernível (UF) }\end{array}$ & $\begin{array}{l}\text { Presença de fissuras incipientes permitindo } \\
\text { evidenciar diferentes torrões } \\
\text { Os torrões são facilmente distintos, mas estão unidos } \\
\text { de tal maneira que trazem coesão ao conjunto } \\
\text { Os espaços entre torrões são desenvolvidos não } \\
\text { permitindo assegurar coesão ao conjunto }\end{array}$ \\
\hline
\end{tabular}

Para descrição e mapeamento dos modos de organização, retiraram-se, a cada época de amostragem, três placas por preparo de solo, com aproximadamente $20 \mathrm{~cm}$ de espessura ecom largura e comprimento dependentes do estádio do crescimento do milho ( $30 \times 20,50 \times 30$ e $70 \times 45 \mathrm{~cm})$. Sobre essas, com pequenos toques de faca, como usual mente se procede nos perfis no campo, visando identificar os modos de organização a serem descritos, foram delimitados os diferentes estados estruturais, caracterizados segundo a descrição do quadro 1. Procedeu-se, então, à confecção dos mapas em plástico transparente sobreposto às placas. Os mapas apresentados no presente trabal ho referemse à última amostragem, visto que as placas, por apresentarem maiores dimensões, permitem mel hor visual ização da distribuição das estruturas no perfil, sendo esteacompanhado pelo perfil de enraizamento.

Em seguida ao mapeamento, nas terceira equarta amostragens, foram retiradas das pranchas, para cada estrutura, amostras indeformadas com anéis vol umétricos para caracterização do estado interno dos torrões do solo mediante a determinação de densidade do solo (Blake, 1965), resistência ao penetrômetro modelo CATL 719-40 com área seccional de $0,196 \mathrm{~cm}^{2}$, porosidade total, macro e microporosidade (Kiehl, 1979). O número de repetições das amostras variou com a freqüência de aparecimento de cada modo de organização e com a área que este ocupava nos mapas confeccionados (13 repetições para UF, 9 para UD e 18 para M ), pois, em algumas situações, o diâmetro dos anéis era superior às áreas das estruturas. As leituras da resistência à penetração foram executadas nas amostras com umidade do solo correspondente a $6 \mathrm{kPa}$ de sucção, sucção esta também utilizada para definição de macro e microporosidade. Amostras correspondentes ao modo de organização $L$ não foram retiradas, visto que essa estrutura encontravase muito solta, ocupando pequenas áreas dos perfis estudados.
Os dados de raízes foram obtidos por meio dos métodos da parede do perfil e do monolito (prancha com pregos) (Bohm, 1979), com três repetições por tratamento, a cada época de amostragem. O primeiro método fornece resultados qualitativos, verificandosea obtenção dos resultados após a del imitação das áreas com diferentes estruturas e confecção dos mapas. Sobre esta mesma face, colocou-se uma malha com quadrículas de $2,5 \times 2,5 \mathrm{~cm}$ e procedeuseà contagem das raízes. Os valores utilizados foram de 0 , para ausência de raízes; 1, para uma raiz; 2 , para duas, e 3, para três ou mais raízes.

Com a utilização do método do monolito, foram obtidos dados quantitativos e representações pictoriais. Depois do mapeamento dos modos de organização dos torrões, da contagem das raízes e da retirada das amostras indeformadas do solo, as placas foram niveladas com espátula até $6 \mathrm{~cm}$ de espessura, sendo então colocadas em água para posterior lavagem. Ao final dessa operação, foram feitas fotografias. Na última amostragem (florescimento), as raízes foram coletadas e acondicionadas em baixas temperaturas para a determinação de parâmetros morfológicos (comprimento, raio e volume). Essas foram selecionadas em áreas das placas representativas do efeito de cada preparo e retiradas amostras com dimensões de $5 \times 10 \mathrm{~cm}$, para as profundidades de 0-5 e 10-15 e 10 x $10 \mathrm{~cm}$, para a profundidade de 25$35 \mathrm{~cm}$, no preparo convencional e plantio direto. As amostras do preparo reduzido não foram avaliadas quanto aos parâmetros morfológi cos por problemas de conservação das amostras. O comprimento das raízes foi determinado pelo método descrito por Tennant (1975).

Amostras para anál ises quími cas foram retiradas das placas, por ocasião da terceira amostragem, nas profundidades de $0-2,5,2,5-7,5,7,5-17,5,25-35$ e 40-50 cm, eanal isadas segundo Tedesco et al . (1985).

A análise estatística dos dados relacionados com o efeito dos preparos sobre as características 
morfológicas da raiz, nas diferentes profundidades, foi realizada seguindo o modelo de análise para o del ineamento de blocos ao acaso com parcela subdi vidida. Para os dados da massa da parte aérea, o model o foi o de blocos ao acaso. Os resultados das características físicas de cada modo de organização dos torrões foram analisados de acordo com o método utilizado para delineamentos completamente ao acaso, já que os preparos não foram levados em conta diretamente, mas, sim, as diferentes estruturas criadas ou já existentes no solo. A comparação entre as médias dos tratamentos foi realizada pelo teste deTukey, a $5 \%$.

\section{RESULTADOS E DISCUSSÃO}

\section{E feito do preparo nos modos de organização dos elementos estruturais do solo}

$\mathrm{Na}$ figura 1, estão representados todos os perfis com os modos de organização e os respectivos mapas da presença de raízes sobrepostos. Tais perfis foram descritos durante a última amostragem, no pleno florescimento, encontrando-se nestes os quatrotipos de organização dos elementos estruturais. Visualizou-se na superfície dos perfis revolvidos, onde se trabal hou com o implemento específico em
PC
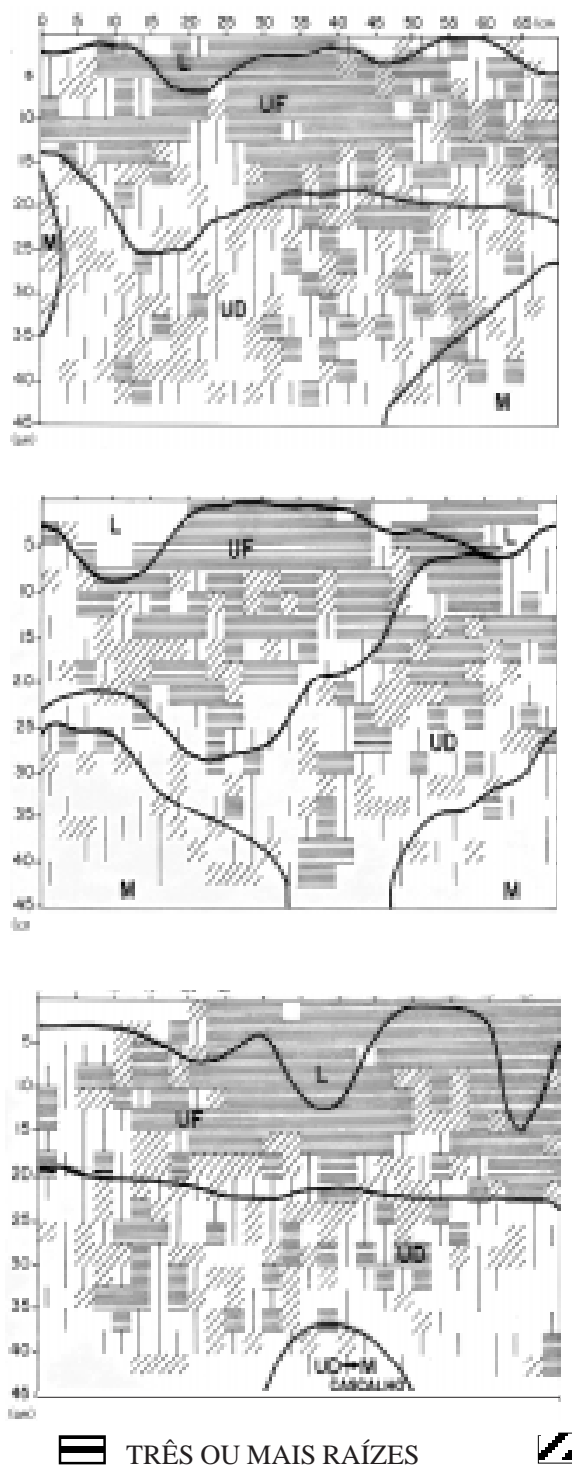

PR
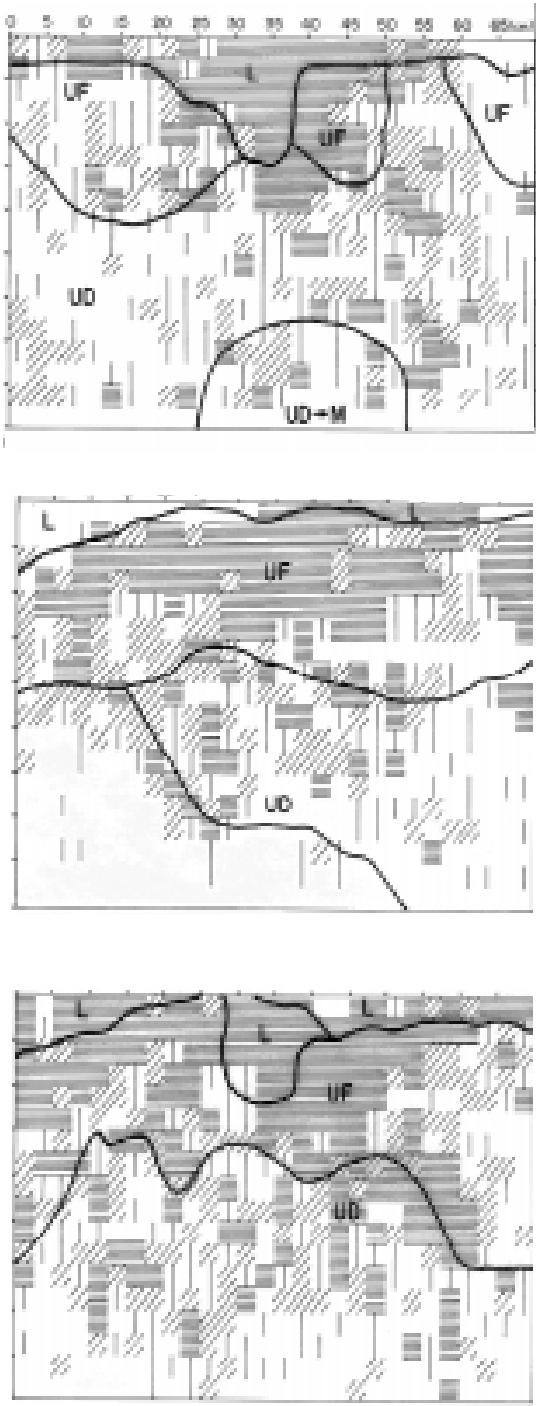

DUAS RAÍZES
PD

I

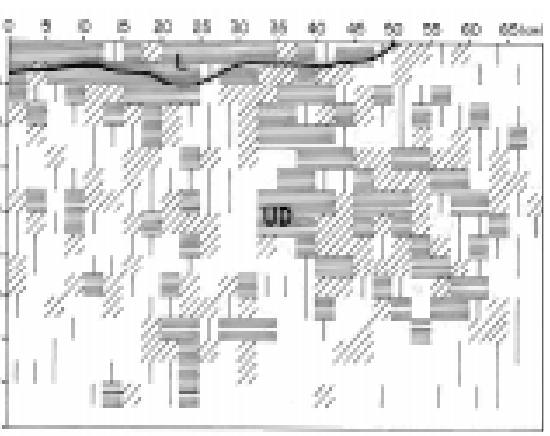

II

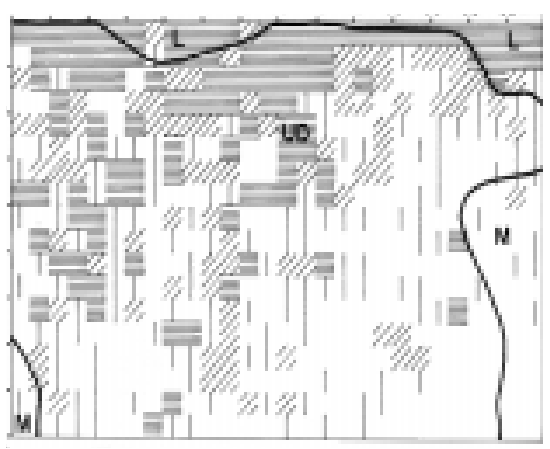

III

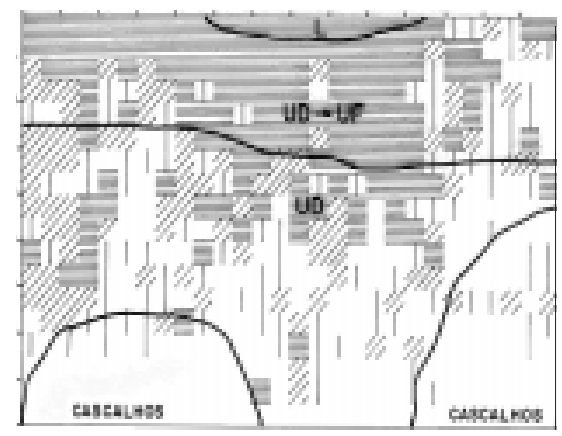

IIII UMA RAIZ

AUSÊNCIA DE RAÍZES

Figura 1. Mapas de modos de organização dos elementos estruturais e perfil de enraizamento do milho, na época do florescimento, em um Podzólico Vermelho-Escuro submetido a preparo convencional (PC), reduzido (PR) e plantio direto (PD) (Repetições I, II e III). 
cada tratamento (arado, seguido de grade ou escarificador), maior vol ume do modo de organização Livre (L), que ocorreu até aproximadamente $15 \mathrm{~cm}$ de profundidade, caracterizando o efeito e a profundidade detrabal ho dos discos e escarificadores no solo. A presença desse modo de organização na superfície dos perfis sob plantio direto foi bastante superficial ereduzida e pode ser atribuída aos sulcos deixados pela semeadura e pelos eventuais aprofundamentos da grade utilizada durante a rolagem da cultura anterior ao milho. Analisando os perfis dos preparos convencional e reduzido, verificou-sea presença do modo de organização Unido Facilmente Discernível (UF), em profundidades variando do limite inferior do Livre até aproximadamente $25 \mathrm{~cm}$. Esse modo de organização ainda seria resultado de fissuras provocadas pelos implementos utilizados. Abaixo do trabalho dos implementos e em quase todo os perfis do plantio direto, apareceram os modos de organização Unido Dificilmente Discernível (UD) e Maciço (M).

No quadro 2, encontram-seos dados quantitativos para caracterização do estado interno dos modos de organização. Os valores para o modo de organização L são médias obtidas por Salton (1991) em amostras retiradas da superfície do preparo convencional. Esses não fizeram parte das análises estatísticas deste trabal ho. $O$ modo de organização UF, o qual é provocado principalmente pel o uso de implementos, apresentou valores de resistência ao penetrômetro mais baixos e porosidade total e macroporosidade mais el evadas em relação ao UD e $M$, que são estruturas mais fechadas e compactadas (Quadro 1). Estes úl timos não diferiram significativamente entre si para as propriedades observadas. Caracterizando este mesmo solo sob diferentes níveis de compactação, em área adjacente ao experimento, Pedó (1986) encontrou para o solo compactado valores para densidade do solo semel hantes ao do modo de organização UD do presente trabal ho, que caracteriza todo o perfil do plantio direto. No entanto, os val ores de macroporosidade para UD encontramse levemente mai ores, indicando possivelmente o resultado do trabalho bi ológico da fauna e das raízes no sentido de formação de bioporos no solo sob plantio direto, como sugerido por Edwards \& Lofty (1978).

A diferença nos valores da porosidade total dos modos de organização deveu-se ao aumento dos macroporos, já que a microporosidade não diferiu significativamente entre os modos de organização. Esse aumento ocorreu como conseqüência da quebra da compactação do perfil por meio do aparecimento de planos de fraqueza entre os agregados e poros de maior tamanho, os quais, segundo Hamblin (1985), desenvolvem-se normalmente entre os torrões ou agregados e são os poros freqüentemente mais afetados por perturbações como as provocadas pela utilização de implementos e por instrumentos de coleta e preparação de amostras. Os valores de $0,06 \mathrm{dm}^{3} \mathrm{dm}^{-3}$ para os macroporos em UD e M são baixos e, apesar de aparentemente limitantes, permitiram o desenvolvimento radicular, o que pode ser visualizado pelos perfis de enraizamento e fotografias (Figuras 1 e 2). Este desenvolvimento podeter ocorrido pel o fato de tais valores terem sido obtidos com seus limites entre macro e microporos determinados na tensão de $6 \mathrm{kPa}$, pois, depois da drenagem e redistribuição da água no solo, a percentagem de poros livres deágua eocupados pelo ar provavelmente torna-se maior. Além disto, os macroporos são os poros mais afetados por perturbações, uma vez que a interface fluido-ar não é controlada por forças capilares e não podem ter seus tamanhos inferidos por meio de curvas características (Hamblin, 1985).

\section{Modo de organização dos elementos estruturais e presença de raízes no perfil}

Pelo exame da figura 1, percebe-se que a maior presença das raízes ocorreu em áreas dos perfis nas quais se detectaram arranjos do tipo L e UF. Esses arranjos, como visto anteriormente, apresentam maior quantidade de poros grandes e planos de fraqueza entre os el ementos estruturais, sendo estes vias preferenciais ao crescimento das raízes por sua baixa resistência (Whiteley \& Dexter, 1983; Ehlers et al., 1983), o que explica, juntamente com a

Quadro 2. Densidade do solo, resistência ao penetrômetro e porosidade de modos de organização dos elementos estruturais caracterizados sob preparo convencional, reduzido e semeadura direta

\begin{tabular}{|c|c|c|c|c|c|}
\hline E strutura & Densidade & Resistência ao penetrômetro & Porosidade total & Macroporosidade & Microporosidade \\
\hline & $\mathrm{kg} \mathrm{dm}^{-3}$ & $\mathrm{KPa}^{(1)}$ & 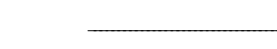 & $\mathrm{dm}^{3} \mathrm{dm}^{-3}$ & - \\
\hline$L^{(2)}$ & 1,4 & - & 0,44 & 0,15 & 0,29 \\
\hline UF & $1,51 \mathrm{a}$ & $769 \mathrm{~b}$ & $0,39 a$ & $0,12 \mathrm{a}$ & $0,27 a$ \\
\hline UD & $1,58 \mathrm{a}$ & $1.478 \mathrm{a}$ & $0,34 \mathrm{~b}$ & $0,06 \mathrm{~b}$ & $0,28 \mathrm{a}$ \\
\hline M & $1,61 \mathrm{a}$ & $1.483 \mathrm{a}$ & $0,34 \mathrm{~b}$ & $0,06 \mathrm{~b}$ & $0,28 a$ \\
\hline
\end{tabular}

Médias, na coluna, seguidas de letras iguais não diferem estatisticamente entre si (Tukey a 5\%).

(1) Medida em amostras submetidas à tensão de 6 kPa. (2) Salton (1991). 
presença dos nutrientes (Quadro 3), a maior quantidade deraízes nessa região. A presença dessas raízes foi reduzida nos arranjos do tipo UD, apesar do desenvolvimento de considerável número de raízes na superfície dos perfis da segunda eterceira repetição do plantio direto. Uma redução pronunciada da presença das raízes ocorreu em regiões onde foram detectados o modo de organização $\mathrm{M}$ e a presença de cascal hos.

Embora os modos de organização expliquem, de maneira geral, a distribuição das raízes, observamse algumas áreas em que sua presença é reduzida, mesmo que o modo de organização tenha permitido em regiões adjacentes o seu aparecimento em quantidade, como no UF do preparo reduzido (primeira repetição) eUD do plantio direto (segunda repetição). Sendo assim, a coincidência entre os modos de organização e a presença das raízes não é perfeita.Tal fatojustifica-se provavelmente pela não determinação da Iocalização específica de cada amostra retirada em cada modo de organização. Por conseguinte, essa variabilidade dentro dos mesmos arranjos indica que, quando se decide utilizar o método adaptado para entendi mento da distribuição das raízes, faz-se necessária a descrição da localização, provavel mente pel o uso de coordenadas ("grid") das amostras em que será quantificado não só o estado interno do arranjo, mas também considerada a presença dos nutrientes nas diferentes camadas do solo.

\section{Expansão do sistema radicular durante o ciclo da cultura}

As fases distintas de desenvol vimento do sistema radicular do milho podem ser acompanhadas pela figura 2. O primeiro estádio de crescimento (20 e 30 dias) é caracterizado principalmente pela direção diagonal assumida pela raiz. Essa direção foi seguida por raízes crescendo sob preparo convenci onal, sendo esse padrão totalmente desviado quando elas se desenvolviam sob plantio direto, onde encontravam posição quase perpendicular ao col mo da planta. No preparo reduzido, as raízes apresentaram comportamento intermediário. Nas fases iniciais do crescimento do milho, Chaudhary \& Prihar (1974), estudando o efeito da presença da pal ha e do cultivo na distribuição das raízes, também observaram um crescimento lateral maior e uma profundidade de enraizamento menor, quando estas estavam apenas sob a influência da palha, com o oposto ocorrendo quando a influência era apenas do cultivo.

No estádio seguinte, 58 dias após o plantio, este padrão diagonal desaparece, ocorrendo a ocupação da camada superior do solo $(30-35 \mathrm{~cm})$ e o aparecimento deraízes secundárias. Nota-sea perda de diferenciação entre os tratamentos (Figura 2), permanecendo ainda evidente a maior presença de raízes nos primeiros cinco centímetros do solo submetido ao plantio direto, como conseqüência da presença das raízes na faseanterior do crescimento.

Quadro 3. Características químicas do solo (PE ) da área experimental, submetida a preparo convencional (PC), preparo reduzido (PR) e plantio direto (PD)

\begin{tabular}{|c|c|c|c|c|c|c|c|c|c|c|c|}
\hline Preparo $^{(1)}$ & Profundidade & pH & $\mathbf{P}$ & $\mathbf{K}$ & $\mathrm{Ca}$ & Mg & Al & $\begin{array}{c}\mathbf{S} \\
\text { efetiva }\end{array}$ & $\begin{array}{c}\text { CTC } \\
\text { efetiva }\end{array}$ & Saturação Al & C \\
\hline & $\mathrm{cm}$ & $\left(\mathrm{H}_{2} \mathrm{O} \quad 1: 2,5\right)$ & $\mathrm{mg} \mathrm{dm} \mathrm{m}^{-3}$ & & 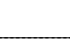 & $-m$ & $\mathrm{O}_{\mathrm{c}} \mathrm{kg}$ & 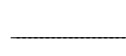 & - & $\%$ & $\mathrm{~g} \mathrm{~kg}^{-1}$ \\
\hline PC & $\begin{array}{c}0-2,5 \\
2,5-7,5 \\
7,5-17,5 \\
25 \\
40\end{array}$ & $\begin{array}{l}4,7 \\
4,7 \\
4,9 \\
4,4 \\
4,6\end{array}$ & $\begin{array}{r}101 \\
128 \\
78 \\
6 \\
1\end{array}$ & $\begin{array}{l}3 \\
3 \\
3 \\
1 \\
1\end{array}$ & $\begin{array}{l}27 \\
29 \\
31 \\
20 \\
19\end{array}$ & $\begin{array}{l}11 \\
12 \\
13 \\
12 \\
13\end{array}$ & $\begin{array}{r}5 \\
4 \\
4 \\
15 \\
19\end{array}$ & $\begin{array}{l}41 \\
44 \\
47 \\
33 \\
33\end{array}$ & $\begin{array}{l}46 \\
48 \\
51 \\
48 \\
52\end{array}$ & $\begin{array}{r}11,0 \\
8,3 \\
7,8 \\
31,2 \\
36,5\end{array}$ & $\begin{array}{c}19,1 \\
17,7 \\
18,3 \\
16,0 \\
-\end{array}$ \\
\hline PR & $\begin{array}{c}0-2,5 \\
2,5-7,5 \\
7,5-17,5 \\
25 \\
40\end{array}$ & $\begin{array}{l}4,8 \\
5,0 \\
4,8 \\
4,3 \\
4,3\end{array}$ & $\begin{array}{r}209 \\
155 \\
80 \\
6 \\
1\end{array}$ & $\begin{array}{l}5 \\
4 \\
2 \\
1 \\
1\end{array}$ & $\begin{array}{l}34 \\
29 \\
28 \\
23 \\
19\end{array}$ & $\begin{array}{l}16 \\
13 \\
13 \\
12 \\
12\end{array}$ & $\begin{array}{r}1 \\
2 \\
3 \\
21 \\
22\end{array}$ & $\begin{array}{l}55 \\
46 \\
43 \\
36 \\
32\end{array}$ & $\begin{array}{l}56 \\
48 \\
46 \\
57 \\
54\end{array}$ & $\begin{array}{r}1,8 \\
4,2 \\
6,5 \\
36,8 \\
40,7\end{array}$ & $\begin{array}{l}24,4 \\
20,5 \\
19,0 \\
16,0 \\
-\end{array}$ \\
\hline PD & $\begin{array}{c}0-2,5 \\
2,5-7,5 \\
7,5-17,5 \\
25 \\
40\end{array}$ & $\begin{array}{l}5,3 \\
4,8 \\
4,4 \\
4,4 \\
4,3\end{array}$ & $\begin{array}{r}259 \\
217 \\
35 \\
3 \\
1\end{array}$ & $\begin{array}{l}5 \\
3 \\
2 \\
2 \\
2\end{array}$ & $\begin{array}{l}40 \\
29 \\
20 \\
19 \\
20\end{array}$ & $\begin{array}{l}15 \\
12 \\
09 \\
10 \\
10\end{array}$ & $\begin{array}{r}1 \\
4 \\
9 \\
17 \\
19\end{array}$ & $\begin{array}{l}60 \\
44 \\
31 \\
31 \\
32\end{array}$ & $\begin{array}{l}61 \\
48 \\
40 \\
48 \\
51\end{array}$ & $\begin{array}{r}1,6 \\
8,3 \\
22,5 \\
35,4 \\
37,3\end{array}$ & $\begin{array}{c}26,9 \\
21,5 \\
21,9 \\
16,5 \\
-\end{array}$ \\
\hline
\end{tabular}

(1) $\mathrm{PC}=$ preparo convencional. $\mathrm{PR}=$ preparo reduzido. $\mathrm{PD}=$ plantio direto. 

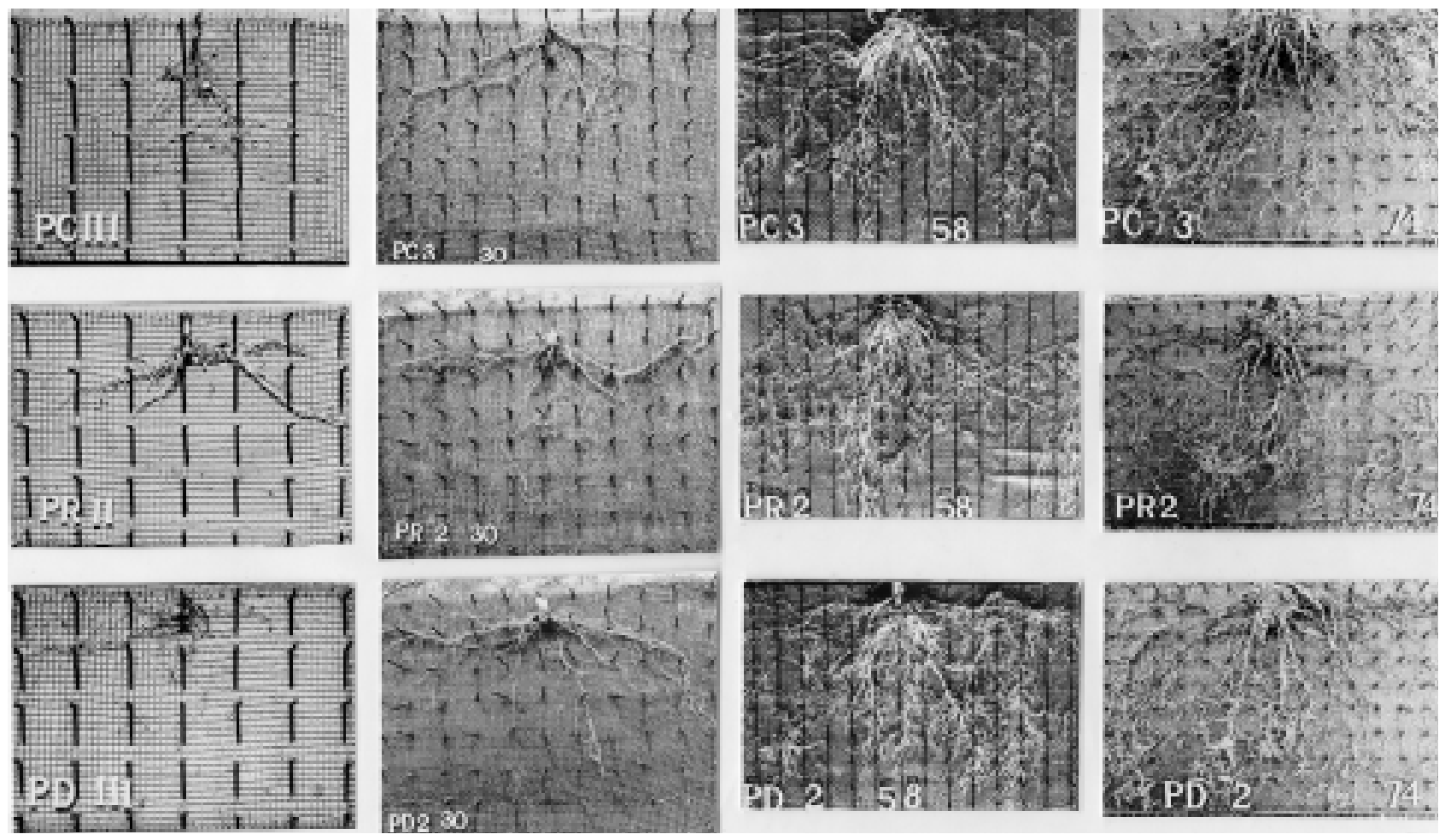

Figura 2 - Raízes de milho sobre pranchas com pregos em diferentes fases de crescimento da cultura (20, 30, 58 e 74 dias após plantio) sob preparo convencional (PC), reduzido (PR) e plantio direto (PD).

Nessesistema, as raízes desenvolveram-seem meio mais coeso, o que fez com que, inicialmente, se concentrassem mais na superfície, já que o desenvolvimento em profundidade ocorre provavelmente quando a raízes encontram vias de crescimento fora da matriz do solo, representadas por canais de raízes e de invertebrados e fissuras (E dwards \& Lofty, 1978; Ehlers et al., 1983). Condições para o estabelecimento dessas vias de crescimento como o não-revol vimento do sol o, menores valores e menores oscilações de temperatura, melhor conservação e teores mais el evados de umidade (Salton, 1991) e maior teor de matéria orgânica (Quadro 3) - foram observadas nesse sistema.

O grande crescimento em extensão e o crescimento em profundidade são as características da próxima fase. A amostragem aos 74 dias representa este estádio, no qual se percebe o desenvol vimento das raízes atéa profundidadefinal da placa.

Todas as fases descritas anteriormente foram caracterizadas por Foth (1962). Para o autor, oúltimo estádio seria definido quando as plantas estivessem na fase de maturação das sementes, sendo o crescimento não mais significativo, o que provavel mente ocorreria para todos os tratamentos se mais uma amostragem fosse realizada.

\section{E feito dos preparos sobre a morfologia das raízes}

O quadro 4 apresenta os dados de parâmetros morfológi cos das raízes de milho, na última data de amostragem, em função dos preparos (convencional e direto) e das profundidades. Nota-se que, na superfície (0-5 cm), a densidade de comprimento da raiz sob plantio direto foi significativamente maior que sob preparo convencional, sendo esta situação invertida nos $10-15 \mathrm{~cm}$ de profundidade. Abaixo da camada trabalhada $(25-35 \mathrm{~cm})$, os preparos apresentaram iguais valores de densidade de comprimento. Tal comportamento é devido ao fato de ser o desvio do crescimento padrão do milho bem visualizado sob plantio direto, no início do ciclo da cultura. Como o preparo convencional não sofreu deflexão no ângulo normal de crescimento por ocasião da fase de ocupação dos primeiros $30 \mathrm{~cm}$ do solo pelas raízes, essas se desenvolveram mais na camada trabalhada, cuja estrutura provocada pelo implemento permitiu seu aprofundamento. Em razão da estrutura mais rígi da no plantio direto, as raízes permaneceram na superfície. Essa presença, al iada à boa conservação de umi dade (Salton, 1991) e aos el evados teores de nutrientes (Quadro 3), fez com que se desenvolvesse maior densidade de comprimento nessa região do perfil. Barber (1971) e Ehlers et al. (1983) encontraram disposição semelhante para milho e aveia, respectivamente. 
Quadro 4. Densidade de comprimento, raio médio e densidade de área de raízes de milho (florescimento) sob preparo convencional (PC) e plantio direto (PD)

\begin{tabular}{|c|c|c|c|c|c|c|}
\hline \multirow[t]{2}{*}{ Profundidade } & \multicolumn{2}{|c|}{ Densidade de comprimento } & \multicolumn{2}{|c|}{ Raio médio } & \multicolumn{2}{|c|}{ Densidade de área } \\
\hline & PC & PD & PC & PD & PC & PD \\
\hline $\mathrm{cm}$ & \multicolumn{2}{|c|}{$\mathrm{cm} \mathrm{cm}^{-3}$} & \multicolumn{2}{|c|}{$\mathrm{mm}$} & \multicolumn{2}{|c|}{$\mathrm{mm}^{2} \mathrm{~cm}^{-3}$} \\
\hline $0-5$ & A $1,7 \mathrm{~b}$ & A 4,2 a & B $0,11 \mathrm{a}$ & B $0,14 \mathrm{a}$ & B $11,7 \mathrm{~b}$ & A 34,6 a \\
\hline $10-15$ & A 3,1 a & B $1,8 \mathrm{~b}$ & A $0,15 b$ & A 0,19 a & A 29,8 a & A $20,9 a$ \\
\hline $25-35$ & A $1,7 \mathrm{a}$ & B 1,8 a & A $0,17 \mathrm{~b}$ & A $0,21 \mathrm{a}$ & AB 17,9 a & A $24,1 \mathrm{a}$ \\
\hline
\end{tabular}

Valores seguidos de mesma letra maiúscula, nas colunas, eminúsculas, nas linhas, não diferem entresi peloteste deTukey (P <0,05).

Com relação ao raio médio das raízes, o plantio direto apresentou, quando comparado ao preparo convencional, raízes com valores mais el evados em todas as profundidades. Tal diferença foi significativa nos $10-15$ e $25-35 \mathrm{~cm}$. Esses valores de raio médio devem-se, provavel mente, às mai ores concentrações de alumínio em profundidade, aliadas à resistência encontrada pelas raízes nos diferentes preparos (Quadros 2 e 3), uma vez que essas el evadas concentrações e os meios rígidos com resistências mais el evadas levam as raízes a sofrerem deformações morfológicas exteriorizadas pelo aumento doraio, o qual, segundo Bengough \& Mullins (1990), resulta principalmente de um aumento na espessura do córtex, sendo isso conseqüência tanto do aumento do diâmetro das células externas, como do aumento do número de células por unidade de comprimento de raiz. A disposição das raízes também é alterada, passando os pêlos radiculares a se desenvolverem próximos à extremidade da raiz eas raízes laterais a ocorrerem juntas, ao longo do eixo principal (Goss \& Russel, 1980).

A densidade de área radicular na superfície do sol o sob plantio direto foi quase duas vezes mai or do que no plantio convencional. Essa diferença dá-se tanto pel o mai or raio como pela maior densidade de comprimento. N este caso, a absorção de nutrientes pode ser mais el evada em razão do mai or volume de solo explorado pela raiz, pela sua maior densidade de comprimento, como pel o maior raio médio, o qual faz com que ocorra maior absorção por centímetro de raiz (Anghinoni \& Barber, 1980). Na camada de 10-15 cm, o aumento da área radicular no preparo convencional ocorre em função da maior densidade de comprimento, o que se deve traduzir em absorção mais eficiente em função da mel hor distribuição de raízes enutrientes nessa camada. Abaixo da camada trabalhada, a diminuição da densidade de comprimento sofrida no preparo convencional é suficiente para inibir o efeito do raio, levando, assim, a uma menor densidade de área em relação à profundidade anterior.
Apesar do comportamento diferenciado dos parâmetros morfológicos, a distribuição final de massa de raízes por profundidade não foi significativamente diferente entre os preparos. Essa diferença, da mesma forma, não se refletiu na produção final da parte aérea nem no rendimento da cultura do milho (Quadro 5), o que pode ser explicado pelo fato de que, apesar da diferença nos parâmetros morfológicos e distribuição das raízes no perfil nas fases iniciais do crescimento, nenhum fator determinante do crescimento foi limitante nestas áreas ao ponto de interferir de maneira diferenciada no crescimento final das plantas, o que vem de acordo com Taylor \& Brar (1991). Segundo esses autores, a menos que algum fator de crescimento da planta venha a ser limitante neste processo, mudanças no sol o que possam influenciar fluxos e concentrações de cada requerimento não afetarão o crescimento da planta, e assim, conseqüentemente, seu rendimento.

Quadro 5. Rendimento de grãos de milho relacionado com preparo convencional $(\mathrm{PC})$, preparo reduzido (PR) e plantio direto (PD)

\begin{tabular}{cc}
\hline Sistema de preparo & Rendimento \\
\hline & $\mathrm{t} \mathrm{ha} \mathrm{h}^{-1}$ \\
PC & $4,85 \mathrm{a}$ \\
PR & $4,77 \mathrm{a}$ \\
PD & $4,68 \mathrm{a}$ \\
\hline
\end{tabular}

$\overline{\text { Médias seguidas de mesma letra não diferem entre si pelo teste }}$ deTukey a $5 \%$.

\section{CONCLUSÕES}

1. Os preparos de solo criaram distribuições distintas dos modos de organização dos elementos estruturais no perfil. 
2. Os modos de organização explicaram, de maneira geral, a presença das raízes no perfil, porém a coincidência entre esses não foi perfeita, indicando que, quando se decide utilizar o método do perfil cultural, fazem-se necessárias a descrição e a quantificação localizada do estado interno dos elementos estruturais e das raízes.

3. Os preparos provocaram diferenças na morfologia das raízes. Essas diferenças não se refletiram na distribuição de massa de raiz em profundidade, tampouco no rendimento da cultura.

\section{LITERATURA CITADA}

ANGHINONI, I. \& BARBER, S.A. Phosphorus influx and growth of corn roots as influenced by phosphorus supply. Agron. J ., 72:685-688, 1980.

BARBER, S.A. Effect of tillage practice on corn (Zea mays L.) root distribution and morphology. Agron. J., 63:724-726, 1971.

BENGOUGH, A.G. \& MULLINS, C.E. Mechanical impendance to root growth: a review of experimental thechniques and root growth response. J. Soil Sci., 41:341-358, 1990.

BLAKE, G.R. Bulk density. In: BLACK, C. A., ed. Methods of soil analysis. Part 1. Madison, American Society of Agronomy, 1965. 770p.

BOHM, W. Methods of studing root system. Berlin, Springer, 1979. $188 \mathrm{p}$

CHAUDHARY, M.R. \& PRIHAR, S.S. Root development and growth response of corn following mulching, cultivation or interrow compaction. Agron. J., 66:350-355, 1974.

EDWARDS, C.A. \& LOFTY, J. R. The influence of arthropods and earthwarms upon root growth of direct drilled cereals. J. Appl. Ecol., 15:789-795, 1978.

EHLERS, W.; KOPKE, U.; HESSE, F. \& BOHM, W. Penetration resistance and root growth of oats in tilled and untilled loess soil. Soil Til. Res., 3:261-275, 1983.
FOTH, H.D. Root and top growth of corn. Agron. J., 54:49-52, 1962.

GAUTRONNEAU, Y. \& MANICHON, H. Guide methodique du Profil Cultural. Paris, CEREF-GEARA, 1987. 71p.

GOSS, M.J . \& RUSSEL, R.S. Effects of mechanical impedance on root growth in barley (Hardeum vulgare L.). III. Observation on the mechanism of response. J. Exp. Bot., 31:577-588, 1980.

HAMBLIN, A.P. The influence of soil structure on water movement, crop root growth, and water uptake. Adv. Agron., 38:95-158, 1985.

KIEHL, E.J . Manual de edafologia. São Paulo, Ceres, 1979. 263p.

PEDÓ, F. Rendimento e distribuição de raízes de seis espécies de plantas em dois níveis de compactação do solo. Porto Alegre, Faculdade de Agronomia, 1986. UFRGS. 92p. (Tese de Mestrado)

ROTH, C.H.; MEYER, B.; FREDE, H.G. \& DERPSCH, R. Effect of mulch rates and tillage systems on infiltrability and other soil physical properties of an Oxisol in Paraná, Brazil. Soil Til. Res., 11:81-91, 1988.

SALTON, J.C. Relação entre sistemas de preparo, temperatura e umidade do solo. Porto Alegre, Faculdade de Agronomia, UFRGS, 1991. 92p. (Tese de Mestrado)

TAYLOR, H.M. \& BRAR, G.S. Effect of soil compaction on root development. Soil Til. Res., 19:111-119, 1991.

TEDESCO, M.J.; VOLKWEIS, S.J . \& BOHNEN, H. Análises de solo, plantas e outros materiais. Porto Alegre, Universidade Federal do Rio Grande do Sul, 1985. 190p.

TENNANT, D. A test of a modified line intersect method of estimating root length. J. Ecol., 63:995-1001, 1975.

VIEIRA, M.J . \& MUZILLI, O. Características físicas de um Latossolo Vermelho Escuro sob diferentes sistemas de manejo. Pesq. Agropec. Bras., 19:873-882, 1984.

WHITELEY, G.M. \& DEXTER, A.R. Behaviour of roots in cracks between soil peds. Plant Soil, 74:153-162, 1983. 